\title{
Assessment of Effects on Prolonged Usage of Face Mask by ENT Professionals During Covid-19 Pandemic
}

\author{
K. Priya ${ }^{1}$ (I) P. N. Aswin Vaishali $^{1} \cdot$ S. Rajasekaran $^{1} \cdot$ D. Balaji ${ }^{1}$ 'R. B. Namasivaya Navin ${ }^{1}$
}

Received: 31 May 2021 / Accepted: 2 October 2021 / Published online: 8 October 2021

(C) Association of Otolaryngologists of India 2021

\begin{abstract}
The protection efficacy of face masks during this covid 19 pandemic has been well documented. The changes in human nasal functions after wearing facemask for prolonged period is not known. The aim of this study is to determine the effects of prolonged usage of facemask by ENT professionals during covid 19 pandemic. It is a cross sectional study conducted in department of ENT in Chettinad Hospital and Research Institute, Kelambakkam. A self-constructed questionnaire containing 21 queries regarding the effects of prolonged use of face mask, after being analysed by the experts of our institution were distributed to 124 ENT professionals all over India. People who are ENT by professionals can participate in this study. Participation is voluntary. Study period was from March 2020 to December 2020. All answered questionnaires were sent for statistical analysis. $63.71 \%$ experienced difficulty in breathing while wearing face mask, $37.10 \%$ experienced dry nose, $46.77 \%$ experienced dry mouth. The most common modality of prevention in an OPD setup was face mask with face shield (31.45\%). About $80.65 \%$ people believed there are side effects due to wearing mask. Since facemasks are essential to protect us from COVID-19, certain strategies can be followed to reduce the discomfort due to its prolonged usage such as encouraging nasal breathing, taking short breaks from wearing mask in a safe environment and to maintain hydration.
\end{abstract}

Keywords Covid 19 - Face masks - ENT professionals . Side effects - Global pandemic

K. Priya

catchpriya.29@gmail.com

1 Department of ENT, Chettinad Hospital and Research Institute, Chennai, India

\section{Introduction}

On March 11, 2020, the World Health Organization declared COVID-19 to be a global pandemic. At the time of the announcement, the global number of COVID-19 cases was increasing day by day, and five months later, worldwide cases continued to increase. COVID-19 is spread by respiratory droplets, and healthcare professionals are mandated to wear PPE when caring for COVID-19 patients. PPE kit contains gowns, pair of gloves, masks, and face shields. Facemasks and respirators are important components of personal protective equipment for health care workers in hospitals and public civilians during these pandemic.

Normally, slight fluctuations in the external environment can affect the function of cilia. Dry conditions and extreme cold conditions can hinder ciliary action thereby stopping ciliary movements at temperatures below $10{ }^{\circ} \mathrm{C}$ and temperatures above $45^{\circ} \mathrm{C}$ [1]. The primary function of the nose is to humidify, warm the inspired air and also aids at removing the harmful and micro particles from entering into the lower respiratory tract. An average adult usually inspires about $10,000 \mathrm{~L}$ of air daily. Nasal mucosa is a highly vascular structure and has a large surface area of $150 \mathrm{~cm}$ square. Physiologically, 50\% resistance in the entire airway is maintained by the nose, when these function gets affected it results in total respiratory function. All of these components contribute to normal homeostasis of the body [1].

Facemasks are of vital importance in protecting the healthcare workers from the Corona virus disease (SARSCOV 2) [2]. Wearing masks for a prolonged period of time causes a host of physiologic and psychologic burdens and can decrease work efficiency. And it also affect the wearer's whole body thermal sensation. Prolonged use of face 
masks causes physical adverse effects such as headaches, difficulty breathing, acne, skin breakdown, rashes, and impaired cognition. It also interferes with vision, communication, and thermal equilibrium (Table 1).

The aim of this study is to determine the various adverse effects of prolonged usage of facemasks which results in poorer adherence and increased risk of susceptibility to infection.

\section{Methods}

A self-constructed questionnaire was made based on pilot study and it was further analysed and assessed by the experts. A final questionnaire of 21 were given to the participants which includes type of mask used, duration, difficulty in breathing, dryness of nose, dryness of mouth, nasal irritation, nasal itching, sweating, headache. And questions like side effects of using face mask, how they dispose the mask, how often they reuse, how they sterilize, do they touch the outer aspect while using.

This is a Cross-sectional study conducted in Chettinad Hospital and Research Institute, Kelambakkam. A total of
124 ENT professionals were analysed during this study period.

Inclusion criteria includes ENT professionals those who are willing for the study. Exclusion criteria included nonhealthcare workers and medical practitioner except ENT. All answered questionnaires were sent for statistical analysis by One sample $\mathrm{T}$ test. The tests used are one sample $\mathrm{T}$ test, $p$ value significance, mean and standard deviation, frequency and percentage. To find the association between the variables one sample $\mathrm{T}$ test is used and $p$ value more than 0.05 was considered as significant. For descriptive variables, mean and standard deviation (continuous variables), frequency and percentage (categorical variables) is used (Table 2).

\section{Results}

A total of 124 ENT professionals were given the questionnaire of which females were $59(47.58 \%)$ and males were $65(52.42 \%)$. All the 124 ENT professionals were included in the final analysis. Most of the study population were in the 25-35 years age group (66.13\%). The most

Table 1 One-sample statistics

\begin{tabular}{|c|c|c|c|c|}
\hline & $\mathrm{N}$ & Mean & SD & SE mean \\
\hline Age & 124 & 1.540 & .8871 & .0797 \\
\hline Gender & 124 & 1.476 & .5014 & .0450 \\
\hline Designation & 124 & 2.484 & 1.2909 & .1159 \\
\hline 1. How long do you use facemask & 124 & 2.347 & .7105 & .0638 \\
\hline 2. Do you have difficulty in breathing while using face mask & 124 & 637 & .4828 & .0434 \\
\hline 3. Do you have dryness of nose while using face mask & 124 & .371 & .4850 & .0436 \\
\hline 4. Do you have dryness of mouth while using face mask & 124 & .468 & .5010 & .0450 \\
\hline 5. Do you have nasal skin irritation/discolouration/scar while using for prolonged time & 124 & .573 & .4967 & .0446 \\
\hline 6. Do you have nasal itching while using mask for prolonged time & 124 & .492 & .5020 & .0451 \\
\hline 7. Do you have sweating over the mask covered area while on mask & 124 & .831 & .3766 & .0338 \\
\hline 8. Are you experiencing headache while using face mask & 124 & .395 & .4909 & .0441 \\
\hline 9. What will you do when you experience headache & 124 & 2.121 & .9844 & .0884 \\
\hline 10. Do you think there are side effects by wearing face mask for longer duration & 124 & .806 & .3967 & .0356 \\
\hline 11. Do you think prolonged use of face mask will impair your normal nasal air flow & 124 & 629 & .4850 & .0436 \\
\hline 12. Do you feel comfortable/not comfortable while using mask & 124 & 1.750 & .4348 & .0390 \\
\hline 13. How do you dispose face mask after using & 124 & 1.492 & .5020 & .0451 \\
\hline 14. How often do you reuse the mask & 124 & 1.774 & .6966 & .0626 \\
\hline 15. How will you sterilize your mask & 124 & 2.661 & .7087 & .0636 \\
\hline 16. Do you discard the mask if you cough/sneeze while using mask & 124 & .573 & .4967 & .0446 \\
\hline 17. While examining the patient in OPD setup the modality of prevention in contracting the COVID 19 & 124 & 2.218 & 1.0005 & .0898 \\
\hline 18. While using mask if you feel uncomfortable do you remove the mask for sometime & 124 & .774 & .4198 & .0377 \\
\hline 19. Have you ever lowered down your mask in the hospital for any other purpose besides eating or drinking & 124 & .484 & .5018 & .0451 \\
\hline 20. Have you touched the outer aspect of the mask while wearing the mask & 124 & .629 & .4850 & .0436 \\
\hline
\end{tabular}


Table 2 One-sample test

\begin{tabular}{|c|c|c|c|c|c|c|}
\hline & \multicolumn{6}{|c|}{ Test value $=0$} \\
\hline & \multirow[t]{2}{*}{$\mathrm{T}$} & \multirow[t]{2}{*}{ df } & \multirow[t]{2}{*}{$\begin{array}{l}\text { Sig. }(2- \\
\text { tailed) }\end{array}$} & \multirow[t]{2}{*}{$\begin{array}{l}\text { Mean } \\
\text { difference }\end{array}$} & \multicolumn{2}{|c|}{$\begin{array}{l}95 \% \\
\text { Confidence } \\
\text { interval of the } \\
\text { difference }\end{array}$} \\
\hline & & & & & Lower & Upper \\
\hline Age & 19.335 & 123 & .000 & 1.5403 & 1.383 & 1.698 \\
\hline Gender & 32.773 & 123 & .000 & 1.4758 & 1.387 & 1.565 \\
\hline Designation & 21.426 & 123 & .000 & 2.4839 & 2.254 & 2.713 \\
\hline 1. How long do you use facemask & 36.781 & 123 & .000 & 2.3468 & 2.220 & 2.473 \\
\hline 2. Do you have difficulty in breathing while using face mask & 14.695 & 123 & .000 & .6371 & .551 & .723 \\
\hline 3. Do you have dryness of nose while using face mask & 8.517 & 123 & .000 & .3710 & .285 & .457 \\
\hline 4. Do you have dryness of mouth while using face mask & 10.397 & 123 & .000 & .4677 & .379 & .557 \\
\hline 5. Do you have nasal skin irritation/discolouration/scar while using for prolonged time & 12.836 & 123 & .000 & .5726 & .484 & .661 \\
\hline 6. Do you have nasal itching while using mask for prolonged time & 10.913 & 123 & .000 & .4919 & .403 & .581 \\
\hline 7. Do you have sweating over the mask covered area while on mask & 24.562 & 123 & .000 & .8306 & .764 & .898 \\
\hline 8. Are you experiencing headache while using face mask & 8.964 & 123 & .000 & .3952 & .308 & .482 \\
\hline 9. What will you do when you experience headache & 23.993 & 123 & .000 & 2.1210 & 1.946 & 2.296 \\
\hline 10. Do you think there are side effects by wearing face mask for longer duration & 22.638 & 123 & .000 & .8065 & .736 & .877 \\
\hline 11. Do you think prolonged use of face mask will impair your normal nasal air flow & 14.442 & 123 & .000 & .6290 & .543 & .715 \\
\hline 12. Do you feel comfortable/not comfortable while using mask & 44.822 & 123 & .000 & 1.7500 & 1.673 & 1.827 \\
\hline 13. How do you dispose face mask after using & 33.097 & 123 & .000 & 1.4919 & 1.403 & 1.581 \\
\hline 14. How often do you reuse the mask & 28.363 & 123 & .000 & 1.7742 & 1.650 & 1.898 \\
\hline 15. How will you sterilize your mask & 41.817 & 123 & .000 & 2.6613 & 2.535 & 2.787 \\
\hline 16. Do you discard the mask if you cough/sneeze while using mask & 12.836 & 123 & .000 & .5726 & .484 & .661 \\
\hline $\begin{array}{l}\text { 17. While examining the patient in OPD setup the modality of prevention in contracting } \\
\text { the COVID } 19\end{array}$ & 24.684 & 123 & .000 & 2.2177 & 2.040 & 2.396 \\
\hline 18. While using mask if you feel uncomfortable do you remove the mask for sometime & 20.536 & 123 & .000 & .7742 & .700 & .849 \\
\hline $\begin{array}{l}\text { 19. Have you ever lowered down your mask in the hospital for any other purpose } \\
\text { besides eating or drinking }\end{array}$ & 10.738 & 123 & .000 & .4839 & .395 & .573 \\
\hline 20. Have you touched the outer aspect of the mask while wearing the mask & 14.442 & 123 & .000 & .6290 & .543 & .715 \\
\hline 21. Have you touched the outer aspect of the mask while wearing the mask & 14.442 & 123 & .000 & 6290 & .543 & .715 \\
\hline
\end{tabular}

common designation was junior resident (39.52\%) followed by assistant professor (16.13\%). Most of the study population wore the face mask for $4-8 \mathrm{~h}$ per day $(50 \%)$ and most of them used N-95 type of mask for prevention.

Of these 124 participants, $63.71 \%$ experienced difficulty in breathing while wearing face mask, $37.10 \%$ experienced dry nose, $46.77 \%$ experienced dry mouth, $57.26 \%$ experienced nasal skin irritation and discoloration, about $49.19 \%$ developed nasal itching, $83.06 \%$ developed sweating in the mask covered area, $39.52 \%$ experienced headache and $48.39 \%$ removed their mask and take a deep breath when they have headache.

About $80.65 \%$ people believed there are side effects due to wearing mask, $75 \%$ felt uncomfortable while wearing mask and $77.42 \%$ removed their mask when they feel uncomfortable. Most of the people (46.77\%) use their mask on a particular day of a week and then reuse the same mask on the same day over the following two weeks, $55.65 \%$ sterilize their mask by hanging it near the sun exposed area and $57.26 \%$ discard their mask if they cough/sneeze while using mask.

The most common modality of prevention in an OPD setup was face mask with face shield (31.45\%), $48.39 \%$ lowered their face mask in the hospital premises and $62.9 \%$ touched the outer aspect of the mask while wearing it (Fig. 1). 
PERCENTAGE

로 percentage

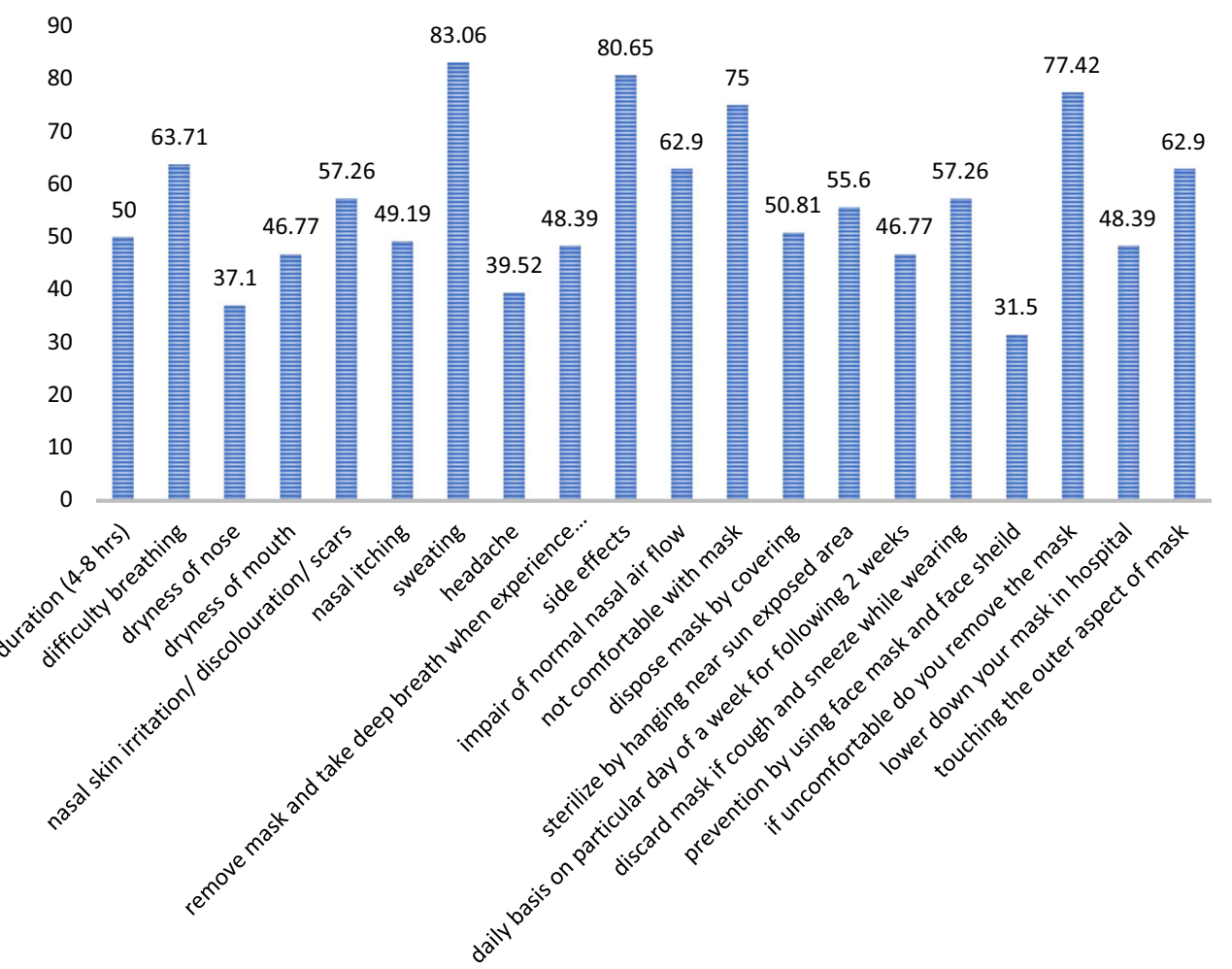

Fig. 1 Percentage results of the questionnaire

\section{Discussion}

In this study, among the 124 participants the result suggests that continuous usage of facemasks can lead to a wide variety of nasal discomfort and side effects pertaining to the nasal skin and mouth due to its prolonged usage. There is a decrease in humidification of air beneath the facemask and decrease in transpiration of the skin around the nasal and perioral region. In this current study, we found that $37.10 \%$ of the participants had dry nose on wearing the mask for a prolonged period of time.

Facemasks protect against harmful pathogens and its use is essential during the pandemic. Masks prevent humidification, increase respiration and temperature in perioral region which could possibly be due to decreased transpiration.

Wearing the facemask for a prolonged period causes reduced heat loss from the body by various mechanisms like conduction, convection, evaporation and radiation [3]. Since facemasks cover both nose and mouth it results in reduction in cooling impact of the facial temperature. DuBois et al. stated that skin temperature $>34.5{ }^{\circ} \mathrm{C}$ is not acceptable because of the increased thermal sensation and results insignificant discomfort to the wearer's [4]. Some studies have stated a high temperature in the cheek region underneath N95 facemasks [5]. In the current study, we found about $83.06 \%$ of ENT professionals have developed excessive sweating around the mouth region. As a result of the discomfort caused by the facemasks, the subjects tend to touch the facemasks at frequent intervals $(62.9 \%)$ and it can lead to contamination of the hands and face leading to more infections.

Another study stated that temperature and the quantity of water delivered by expired air is notably higher with mouth breathing when compared to nasal breathing. In our study also we assessed that about $63.71 \%$ of the participants had difficulty in breathing with the facemasks on. Foo et al., analysed healthcare workers during the SARS pandemic in 2003 at Singapore, and reported that 51.4\% experienced itching induced by face masks [6]. In the current study we found that about $49.19 \%$ of the participants have developed nasal itching.

The study with 124 ENT professionals is adequate enough for the technical hypothesis but insufficient for evaluation of multifactorial effects. If we had involved health care professionals from other specialities in the study, it would result in a significant change in the results of the study. 


\section{Conclusion}

In conclusion, the use of facemask causes significant discomfort to all the participants during its prolonged usage which can limit the efficient usage of facemask, leading to reduced protection. Since facemasks are essential to protect us from COVID-19, certain strategies can be followed to reduce the discomfort due to its prolonged usage such as encouraging nasal breathing, taking short breaks from wearing mask in a safe environment and to maintain hydration.

\section{Acknowledgements Nil.}

\section{Declarations}

Conflict of interest The authors declared that they have no conflict of interest.

Ethical Approval Ethical committee letter has been obtained and letter attached.

Informed Consent Informed consent will be obtained from all the participants who participate in the study.

\section{References}

1. Tira G, Shahzada KA (2018) Physiology of the nose and paranasal sinuses, Chap 89. In: Scott-Brown's otorhinolaryngology head and neck surgery, vol 1, 8th edn. CRC Press, pp 983-988

2. WHO Director-General's opening remarks at the media briefing on COVID-19. Accessed 11 March 2020

3. Wang L, Yin H, Di Y, Liu Y, Liu J (2016) Human local and total heat losses in different temperature. Physiol Behav 157:270-276

4. DuBois AB, Harb ZF, Fox SH (1990) Thermal discomfort of respiratory protective devices. Am Ind Hyg Assoc J 51(10):550-554

5. Li Y, Tokura H, Guo Y et al (2005) Effects of wearing N95 and surgical facemask on heart rate, thermal stress and subjective sensations. Int Arch Occup Environ Health 78:501-509

6. Foo CC, Goon AT, Leow YH, Goh CL (2006) Adverse skin reactions to personal protective equipment against severe acute respiratory syndrome - a descriptive study in Singapore. Contact Dermat 55:291-294

Publisher's Note Springer Nature remains neutral with regard to jurisdictional claims in published maps and institutional affiliations. 